\title{
LA CIUDAD COMO LABERINTO PSICÓTICO EN EL PADRE MÍO Y JAMÁS EL FUEGO NUNCA DE DIAMELA ELTIT
}

\author{
Eugenia Brito Astrosa \\ Universidad de Chile \\ eugeniabrito@hotmail.com
}

\section{RESUMEN/ABSTRACT}

El presente artículo explora las relaciones entre psicosis y normalidad en dos textos escritos por Diamela Eltit, El Padre Mío y Jamás el Fuego Nunca, libros cuya construcción laberíntica espacial y lingüística expresa, de manera barroca, el terror y la violencia como efectos políticos deseados por la tiranía de la dictadura militar instalada en Chile desde 1973 hasta 1989, efectos no reparados durante la posdictadura y cuyas huellas se expanden por el cuerpo de la ciudadanía, a través de la enfermedad, la locura y la muerte.

Palabras clave: laberinto, psicosis, enfermedad, memoria, violencia.

The present article explores relationships between psychosis and normality in two texts written by Diamela Eltit, El Padre Mío and Jamás el Fuego Nunca, are books which, through their spacially and linguistically labyrinthine constructions, express, with a baroque way, terror and violence as the political effects sought after by the military dictatorship installed in Chile from 1973 until 1989; effects never repaired during the post-dictatorship period and which have left a mortal imprint that expands through the body of the citizenship, through sickness, insanity, and death.

KEYWORDS: labyrinth, psychosis, sickness, memory, violence.

En el cuento de Borges La casa de Asterión (1949), el narrador centrado en su personaje protagónico, el Minotauro, ratifica su diferencia con el humano y espera, devorado por el tedio, en el laberinto de Cnossos, el día 
de su liberación. Cuando el héroe mítico, Teseo, lo mata, cree ver en él a su salvador. Tras terminar su tarea, Teseo le dice a Ariadna: "Lo creerás, el Minotauro apenas se defendió" (70).

Cito ese cuento porque en él se encuentra el Minotauro, el verdugo, que es Asterión, esperando la muerte como única salida de la monotonía del laberinto. A partir de ese relato, Borges elabora un texto que desde la perspectiva de la grandiosidad del estilo de héroes y dioses en la épica y tragedia griegas, asume como mediocre la existencia del hombre y desarticula la categoría de la inmortalidad como infinitamente melancólica. El motivo del taedium vitae estructura la idea del laberinto borgiano, en una sola dirección, desplazando el eje de la perspectiva cristiana hacia la teogonía del mundo griego, en que la muerte era válida como coronación de una vida noble en cuanto se cultivara la virtud, demostrada en el equilibrio de mente y cuerpo. El temple de ánimo es el desencanto, la nostalgia por la pérdida de lo sublime en el Minotauro.

Si en el cuento de Borges el laberinto de Cnossos es un conjunto de pistas en que lo real se mezcla con lo posible para conjugar los sentidos de la muerte sacrificial de los jóvenes en esquinas o recodos que recortan los infinitos espacios del palacio del Minotauro, la presencia casi secreta de los cadáveres se disimula con la estructura de múltiples formas del lugar, conformado como la cita arqueológica de una ciudad en que el deseo retiene a la memoria y la muerte, consignada en los crímenes periódicos hacia los jóvenes entregados como piezas sacrificiales. Terror y deseo coexisten en toda la ciudad de Atenas, amenazada por el asesinato implacable y periódico. Pero también Cnossos esconde la clave de la dominación: la figura del Minotauro antropófago es usada para mitigar el odio del rey Minos contra los aqueos, por la muerte de su hijo. El laberinto, pues, esconde no solo el monstruo, también la muerte brutal; el resto constituirá la ornamentación y consagración estéticas de un ser dividido entre lo monstruoso y lo divino; en que las muertes de los jóvenes cada nueve años constituiría la clave alegórica de lo ominoso y del desvarío de quien se encuentra más allá del bien y del mal. Demás está decir que el salvaje Minotauro confirma en su cuerpo la unión del hombre y la bestia; del bien y del mal, lo divino y lo humano. Es para reparar esas muertes de catorce jóvenes que Teseo decide matarlo, convirtiéndose en héroe.

Lo que muestra Borges es el dolor del verdugo y su incapacidad de ver al otro; en este caso, el dolor de las jóvenes víctimas destinadas al sacrificio. Lo que el Mito revela es la fragilidad de la vida humana y el lugar que juega dicha fragilidad en las luchas de poder. El poderoso Minos valiéndose de 
Asterión subordina de manera criminal a los atenienses. Así se disfraza el apetito de matar, otorgándole al crimen un sentido religioso y temible.

De ese modo, el cuento postula la simpleza final de las narraciones humanas, cuya ferocidad enclaustrada en un "laberinto" no es más que la expresión del tedio y de la melancolía, en la que la grandeza de una construcción no es sino la expresión de la insignificancia. El ostentoso laberinto cubre el aburrimiento enorme del monstruo.

Estableciendo una correlación con Borges, lo que encubre el laberinto de Diamela Eltit en El Padre Mio (1998) es la compleja red citadina que oculta y muestra las claves del poder en el discurso y el cuerpo de un habla psicótica, pero que impone su Verdad de una manera poética frente a las represiones ciegas del poder del Imperio y sus tentáculos dictatoriales, centrados en el terror y en la criminalidad. De este modo el laberinto encierra a la manera de un jeroglífico el signo poético que abre el sistema, como a la red de significaciones que portan el lenguaje y su historia.

El laberinto ha sido una de las metáforas mediante las cuales la historia de la literatura latinoamericana ha escogido sus representaciones para hablar de la dificultad de advenir a la autonomía y el libre desarrollo de las utopías que han ido generando su crudo desenlace en la historia de las modernidades y su clausura postmoderna, para dejar pasar la historia, haciéndola circular, echando por tierra los escollos, las dificultades mítico poéticas, políticas e históricas que exigieran en sus articulaciones lógicas la clausura de áreas determinadas de la ciudad.

En las lecturas que propongo hacer, en los textos de Diamela Eltit, El Padre Mío y Jamás el fuego Nunca (2007), el laberinto aparece como un sistema que manifiesta el ímpetu del Imperio y deja pistas sobre la ciudad, entre las cuales se encuentra por un lado, la memoria y la melancolía de la memoria; por otro lado, la psicosis, como el enigma propuesto al frenesí del vértigo circulante. Los signos avanzan en ambos textos en encabalgamientos silábicos. Barthes ha dicho que la cultura falologocéntrica detiene y oculta la codificación de las pistas de circulación, volviendo ciego el vértice de la velocidad. Sin embargo, el nuevo eje de encuentro de las huellas circulantes se encuentran en la enigmática sique, en el cuerpo y el habla del psicótico.

Su enigma cerca el movimiento, obstruye la comunicación, pues contiene como cifra las claves de la circulación cotidiana.

¿Cómo lo hace? Nada más ni nada menos que espacializando el tiempo para generar un espacio poético en que los enunciados lineales de la lengua cultural chilena potencian en sintagmas que abren la "historia", es decir, 
la trama del argumento del texto en un tiempo vertical, en que de manera paradigmática las asociaciones entre hechos similares establecen analogías, abriendo la capacidad evocadora de la memoria para romper el orden lineal, y señalando un nuevo espacio y un sentido otro, imposible, que pone en tela de juicio los significados consensuados, derribando la tiranía y las filiaciones que los estructuran.

La poética escritural de Eltit devuelve la deuda a quienes la cobran como sistema de coacciones y propuestas de jerarquías; echa por tierra las distinciones jerárquicas revelando su carácter arbitrario. El juicio analítico que se desprende del trabajo deconstructivo de su texto es definitivo, en la medida en que incluye la mirada del esquizo como tercer término de la cadena emisor-receptor. Su verdad, aunque es parcial, no es conjetural, en cuanto sigue las leyes de los grupos y lleva las contradicciones a una resolución lógica. Es decir, lo que el ojo analítico del esquizo revela es la caducidad del contrato cultural entre las leyes del tirano y el pueblo dominado.

El laberinto no abre familia, al contrario, revela el carácter retentivo y servil de ese proyecto cultural. El laberinto chileno de la dictadura desafía al héroe (el psicótico de Conchalí) con sus falsas promesas y con lo fabuloso de su apropiación territorial, lo hace mirar la flaqueza de su cometido y la pequeñez de sus actos. Enfrenta no solo a la muerte; el héroe, aquí un antihéroe, un sobreviviente psicotizado por la sociedad de su tiempo, que con su texto oral emplaza y hace jirones el discurso cultural que ha ocupado su cuerpo político, anudándolo en las claves del exilio y la soledad.

Lo hace por medio de la repetición obsesiva de un único significante: la denuncia de la tiranía del padre que le ha confiscado, no solo el cuerpo, sino el país.

Bajo su conciencia que aparenta "fugarse" de la realidad, sostiene la capacidad de señalar la cifra densa y opaca de la empresa de poder que escenificara el régimen y la continuidad histórica de los "nombres" que ese poder ostentara.

El héroe contemporáneo ya no es un hijo de un dios, ha perdido ese fulgor y su apetito de trascendencia. Es ahora un hombre, pero un hombre pequeño y limitado, que pierde su espiritualidad y su gloria, como un molusco, que delimita los sentidos sociales, de los cuales, no obstante, no puede liberarse, pero a los que enjuicia. A pesar de su condición precaria, se enfrenta con los Hados de su tiempo, devolviendo su estatuto a lo reprimido, estableciendo la necesidad de ese retorno en la huella del trauma, único camino posible como diría Freud, para instalar una pregunta sobre los sentidos, entre los cuales 
está la pregunta por la nación, la escritura de la nación y los mitos que éstas han constituido, la validez de las formas de lectura de los tropos y formas que esa escritura ha puesto en marcha, por medio de pactos entre burguesía y capital. Es una demanda que obliga a la enunciación a realizar una suerte de duelo por lo perdido o a llevar en sus hombros la melancolía de no haber podido, no haber querido ni deseado ver más allá de las apariencias externas.

Diamela Eltit, escritora chilena contemporánea, y autora de cerca de veinte textos desde Lumpérica (1983) hasta Fuerzas Especiales (2013), ha atravesado la dictadura y la posdictadura como ciudadana testigo que ha elaborado formas estéticas para hacer frente a los dilemas que el país ha abierto en la cultura local. Sus novelas atraviesan la pregunta sobre cómo puede convivir una ciudadanía frente a sistemas adversos, tiranizados por el capitalismo, a través de la deuda y los préstamos de la banca del primer mundo. Cómo vivir encarando una hegemonía que somete, por el trabajo y el dinero, al mundo chileno, el que encarna la plusvalía de esa mercancía, cuya aura convertida en fetiche se despliega espectacular en las vitrinas de un mundo dominado por la especulación financiera y la sedición militar rendida ante el despotismo de la fanfarrona burguesía de clase alta.

Frente a esos dilemas, el sujeto recortado por los sistemas políticos y económicos, por el discurso social y por la subordinación de la letra a la circulación del capital, Diamela Eltit imagina formas de resistencia. Lo hace desde su primera novela, Lumpérica, en la que a través del dolor y la sangre, del tatuaje de la inscripción en el socius, bajo el control panóptico de un discurso del terror administrado por la dictadura militar vigente en Chile desde 1973 hasta 1989, el que cautelara calles y barrios, plazas y márgenes, sitios en los que de noche una forma mujer abre una zona de descontrol, un flujo desterritorializado, como diría Deleuze. Es decir, una poética que interroga tanto desde su discurso como desde el metadiscurso que abre las condiciones por las cuales se legitima toda enunciación, particularmente la enunciación de los textos culturales de la historia de Chile.

Desde esos pre-textos únicos, el texto que nos ocupa construye una zona de preguntas en el libro. ¿Cuáles son esas zonas?

Una de ellas, la más importante aquí es la mímesis con la que se produce un relato que, situado entre la alegoría y el testimonio, transmite un habla que recortada en un sitio, más allá de la frase, la emplaza desde un espacio transtextual que multiplica el decir y desregula la sintaxis, privándola de su papel ordenador y controlador. Hace saltar el sujeto y el predicado al abismo de la sentencia que encabalga oraciones en la fuga paratáctica de la 
coordinación que multiplica los órdenes y abre nuevos sitios de regulación del decir y de los sentidos. "Pero, debería servir de testimonio yo. Hospitalario no puedo servir, porque ahí tienen empleada la táctica de la complicidad' (de su 'Tercera Habla')." (El Padre 18).

En el sitio eriazo de Conchalí, el psicótico formula el habla desterritorializada del delirio. Este, como toda habla psicótica desentierra los órdenes dominantes, colocándolos todos ellos en un mismo paradigma de dominación, del cual él yace expulsado, expulsado de su lógica dominante y abusadora.

Porque yo fui solicitado para esos cargos y esas garantías, no el Padre mío ni el Sr Colvin que es el Sr. Luengo, que es diputado y senador. A él le ofrecieron esos cargos y esas representaciones; por eso que a mí me planearon por asesinato y enfermo mental. Se pagó un dinero importante por lo mío. El canto hay que superarlo, él es Argentino Ledezma, yo lo superé a él como cantor. A mí me tienen planeado más de veinte años en esos asuntos. Porque yo no quise admitir que ahora, últimamente, me fuera a pasar lo mismo que anteriormente, porque yo fui solicitado para esos cargos, ya que esto me lo planeó antes a mí (El Padre 23).

El capitalismo es entonces el gran dilema de esta primera habla, la arbitrariedad y mala práctica de los que ejercen el poder en la pluralidad de sus múltiples cargos y desde la retórica de la inversión, que camufla el abuso tras la figura de la modernización y de la usura, el lucro, que comparten de manera simultánea o sucesiva, y en las que planifican contra otros. El desalojo de este sujeto desde el poder lo sitúa en una época previa a la que cita el lugar de la enunciación, en el anonimato, en el exilio de los centros: lo llevó a la periferia.

La borradura de la biografía, que nada tiene que ver con la del sujeto, es otro desalojo cuyo rostro es el desamparo, porque el Padre Mío constituye su domicilio en el lenguaje y en la crítica política a un poder que lejos de ser fantasmal, toma nombres: Luengo, Colvin y más adelante, Allende, Alessandri, Pinochet.

El psicótico a través de su delirio formula su ser en el discurso político, el que nada tiene que ver con las peculiaridades del lamento oculto del Edipo, ni con las filiaciones. Tampoco está acompañado de alguna hija, que como Antígona, acepte dar su vida en sacrificio por el padre o los hermanos. No. El país tiene una deuda con él y su exigua existencia. Es desde ese marginal, expuesto en el eriazo desde donde se levanta una guerra civil. Y es la calidad histórica del relato, es el éxtasis vertiginoso de su discurso y su poder 
sintético para denunciar la composición social del país, sus complots, sus asesinos, autodenominados presidentes, lo que sorprende a Diamela Eltit, la que esgrime la zona de enunciación mimética del texto.

Ella lo ve y al oírlo evoca a Beckett, el escritor irlandés que diera vida a los vagabundos, los ancianos pobres y excluidos, los enajenados del mundo capitalista e industrial. Evoca a Beckett y el habla que él construye para escribir desde el fragmentarismo y la elipsis, la ruina contenida en sujetos que apenas sí poseen un lugar en el mundo, sujetos que perdieron la capacidad de construir una subjetividad plena o propia, porque son la ruina, la hilacha de un sistema mortífero en el que ellos derivan sus esquinas asfixiadas, sus galaxias deprivadas de todo, que de esa manera, demuestran sus excesos y abusos.

Entonces Diamela Eltit piensa cómo construir ese relato de El Padre Mio, cómo hacer comparecer el texto de esa historia en la Historia oficial, en el Chile de 1989, fecha de cruce entre el régimen dictatorial y el inicio de la democracia concertacionista.

Como testimonio, sí, dice, pero luego agrega: es-cultura y es una pena.

El Padre mío entonces se convierte en una alegoría de la cultura chilena vista desde su reverso, una escritura que desplaza el canon hasta el absurdo, mostrando su lado enfermo y malvado, su composición abigarrada y grotesca. Como alegoría, se sitúa más allá de la tragedia y de lo patético, pues no busca la lágrima, ni padece la nostalgia del hogar cálido ni del nido amoroso. Es el que enjuicia al tirano, desarticulando ese significante de su poder panóptico hasta llevarlo al desalojo y exposición matérica del eriazo y ésa es la segunda zona de preguntas que bordea el relato.

(...)-¿sabe Ud. porqué los matan?- para quedarse con las propiedades de ellos y por las personas que ocupan cargos y que representan las garantías de ocupar cargos. Ellos no son comunistas aquí. El Padre mío es comunista con la cédula de identidad, pero lo hace por negocio, ya que el Padre mío vive de la usurpación permanentemente con el Sr. Luengo que le sirve para la Antártida. Tiene hombres influyentes que le arreglan los papeles, los archivos que ocupan cargos en el Estado. Se deshizo de ellos ya que ninguna persona que vivió con él le conviene, -por esto que le estoy conversando yo-,-porque él le trabaja a la usurpación permanentemente (El Padre 25-26).

La evocación insistente de la usura, de la ilegalidad, de la planificación de un asesinato oculto tras la trama social, el exilio y la deshonra son los significantes 
que inundan de manera paratáctica el habla desenfrenada y resistente a la jerarquía del orden unido a la gramática que impone la ley de la letra.

\begin{abstract}
¿Sabe por qué le digo esto yo? Porque él es delegado de las Naciones Unidas y por la ley, la razón o la fuerza no puede más que ser socialista si se ponen de acuerdo Uds. Yo tampoco soy partidario de otra cosa. Yo llevo mi existencia en estas condiciones, sabiendo lo que les estoy explicando yo. Pero por la razón o la fuerza es otro asunto de lo que representa ser delegado de las Naciones Unidas, porque representan a la Administración y al personal en general, al cual no se le ha dado cumplimiento. Está esperando la usurpación, una vez más, que por la ley no ha querido solucionar hechos favorables relacionados con el compromiso bancario inclusive. Eso es lo que les converso yo. Es algo de los que oí hablar antes (El Padre 69-70).
\end{abstract}

¿Qué diferencia existe entre el habla de la psicosis y la de la normalidad? Acaso no será que la norma está enteramente codificada por discursos del poder, siendo la expresión más común la que se trenza con la mecánica del biopoder y con la territorialidad de los espacios económicos afines a las alianzas para no llegar nunca a confrontar el ojo del tirano. $\mathrm{O}$ en el caso del neoliberalismo contemporáneo, la norma buscada es aquella que no da con las estructuras que dominan los flujos económicos, para subordinar cuerpos y deseos a su eje único. La norma sería el efecto desarticulador de la subjetividad como territorialidad que se piensa y se elabora, lo que traería como efecto la huella perdida, el residuo o resto confirmando lo que Jean Baudrillard denomina como el éxtasis de la comunicación, es decir, la astilla que mantiene una atención servil ante la gran pantalla de la oferta mediática de los medios de comunicación y la gran vitrina del mercado que asegura que cada sujeto sea la plusvalía del poderoso estado capitalista.

¿Y lo psicótico? Es el estallido del sentido común, la multiplicación de las hablas autónomas que establecen un discurso sin fronteras en el que el yo no es un eje de la enunciación sino la combinación de las cadenas enlazadas por el deseo o por el hambre de una pertinencia social más amplia y favorable, sea éste el mutante edificio de los poderes o la capacidad articulatoria de umbrales y discontinuidades, como hubiera planteado Foucault , la genealogía de los saberes que abre paso a la historia de Occidente.

Nada más que una reserva histórica del sinsentido del país, del borramiento de sus fronteras en que el yo/otro para el Padre Mío se enlaza de manera sospechosa con el señor Colvin, que es el Sr. Luengo, que es el que suspende el 
medicamento que conecta la mente con el poder. Ese medicamento imaginario por el que ruega, suplica a sus interlocutoras para que todos podamos enfrentarnos a la dictadura y sus ilegalidades con el fin de poder discernir mejor un lugar para abrir la democracia o algo cercano a una democracia, un modelo económico, no ladrón ni asesino, como lo ve el dueño de esta habla, para no generar ya el "planeamiento", léase el control de los cuerpos y las mentes sometidas a la desesperada tarea de vivir.

El laberinto es una de las figuras de la imaginación latinoamericana, una figura constituyente del "archivo mítico" de las formas novelísticas de Borges, García Márquez y Donoso. Se trata de proponer una construcción cerrada y compleja, que puede anudarse desde la multiplicidad y la proliferación del barroco hasta llegar a la línea sola y recta como en El jardín de senderos que se bifurcan (1944) de Borges. El laberinto espejea la construcción de la ciudad, citando la errancia, el fantasma, la nostalgia, el deseo, pero también, la fuga. Si el laberinto como enigma está en la sociedad chilena desde 1973 hasta 1989, está en estos textos de Eltit como peregrinaje por la ciudad, y también en los cuartos en los que se refugian los segregados del discurso social, como la pareja de Jamás el Fuego Nunca, buscando claves de articulación de un mundo simbólico que ha quedado en el pasado y que subyace como resta en algunas hablas, entre ellas, en el delirio de ese "loco" de Conchalí, y en la pluralidad barroca de significantes que existen en sus tres hablas, como cita del proyecto que se ha instalado en el país como fuerza y decreto que, suspendiendo el imperio de la letra, de la razón, de la vanguardia y de la utopía social, intercambia esos flujos para derramar sus grandes edificios, con una sociedad basada en la potenciación de la economía, las armas y la ilegalidad.

El laberinto como conjunto de retazos de hablas, jirones de la modernidad, se articula en un diálogo mudo con el proyecto de la dictadura, para hacer germinar la escultura, como la denomina Diamela Eltit. La escultura de las ruinas y su melancolía, el trauma y los nudos patógenos de la enfermedad a la que el nuevo régimen condenara a muchos sobrevivientes.

El otro nombre "es una pena" y el discurso que lo sigue, intenta explicarlo: "jirones de diarios, fragmentos de exterminio, sílabas de muerte, pausas de mentira, frases comerciales, nombres de difuntos. Es una honda crisis del lenguaje, una infección en la memoria, una desarticulación de todas las ideologías. Es una pena" (El Padre 17).

El Padre Mio entonces es un jeroglífico que condensa, desde su exclusión y su aislamiento, la historia chilena, la historia de la sobrevivencia y del horror bajo el régimen dictatorial y de la carencia de sentido de toda pertenencia al 
lugar. Lo que resta es la marginalidad política y la búsqueda, desde la soledad y el vagabundaje, de un lugar posible para los sin patria, y su gesto político, elaborado desde el dolor y el desamparo. Es por ello que la autora lo nombra: "el padre mío", aludiendo con él a la figura sustitutiva del héroe, del caudillo, del guerrillero romántico, del artista. La psicosis sería el estado mental que se insertara en esos años abyectos bajo el artificio de una imagen fascista que, organizada en limitados estereotipos ocultaba su criminalidad bajo el lema: todo está disponible, si te endeudas y ocupas la tarjeta de crédito, todo está disponible, si me obedeces. Estereotipo adoptado no solo por el Estado, sino también por el mercado, que lo oferta en un sueño a plazos muy cercano, en el despertar a la pesadilla.

El Padre mío es un testimonio mediatizado por la escritura de Eltit quien se oculta y se muestra en la figura de la Introducción y de manera más soslayada en la puntuación, que ella otorga al habla delirante del personaje. Es el testimonio de Eltit, de una buena parte de su poética, una poética minoritaria, como lo ha dicho el crítico Juan Carlos Lértora en Una poética de literatura menor: La Narrativa de Diamela Eltit (1993).

Pero no solo es testimonio El Padre Mío, sino también alegoría, red metafórica sobre el país a los diez años de instalada la dictadura, es el cuerpo prohibido e ilegal de la cultura del consumo y del maquillaje del terror y la muerte, El Padre Mio habla de una gloria pasada, que le ha sido arrebatada al país, ¿no será pues, la gloria de la Unidad Popular?; ¿no será la gloria de exhibir como testimonio un cuerpo resistente aún desde la enfermedad a la ilegalidad, el despotismo, la negligencia, el terrorismo, el consumismo y la muerte? Todas esas condiciones lo revisten del aura necesaria para converger como signo poético en el texto, no solo como cita reparadora, sino también como metáfora de una ausencia y una pérdida, es decir como ruina y trauma, privilegiados, porque no se seducen con el espectáculo de la mercancía, no se asustan y se borran tras el artificio de la imagen de moda, no caen.

En Jamás el Fuego Nunca, la penúltima novela de Eltit, el trazado múltiple del significante opone dos núcleos poéticos importantes: la célula como emergencia y resta de toda batalla y una poética de la catástrofe. Esta se lleva a cabo gracias a la metáfora de la limpieza.

Curiosamente, en el mundo del Chile contemporáneo, su carátula fascista y modernizadora ha llegado a proponer lo bello, lo limpio, lo joven como el cuerpo de exhibición de la vitrina posmoderna. Para existir y no ser invisibilizados en el país, los chilenos, subalternos del Primer Mundo, nos 
presentamos, limpios y perfumados como fetiches de un mundo ganador que se presenta con apariencia conquistadora ante el mercado de la metrópolis.

En ese sentido, el único trabajo que se le asigna a la protagonista de esta novela es la limpieza, la higiene de cuerpos en la antesala de la muerte. De esa manera, la narradora observa como en un laboratorio de ensayo los modos en que la vejez y el deterioro cursan sus huellas y surcos por cuerpos ancianos y enfermos, a los que solo un código de honor de las familias mantiene rigurosamente pulcro.

Los cuerpos débiles de los viejos sirven no solo como trabajo sino también como la metáfora en la que se inscribe la catástrofe de manera literal, escritura sin metáfora.

La narración comienza con el recuerdo de Franco, el recuerdo de su muerte, olvidada ya en su carácter apocalíptico, en el momento en que ella y su pareja se abrían a la utopía social propia de la época moderna. El, un líder político, ella una militante de izquierdas empecinados en cambiar la sociedad conservadora chilena, haciendo converger sobre ella un nuevo mito con otros orígenes: el socialismo, la revolución democrática de Allende. Estos recuerdos aparecen como parte de la exégesis del siglo XX.

Exégesis que se abre de manera paralela con una nueva inscripción corporal: la vejez, los cuerpos viejos como excedentes o restos de una historia canibalística de depredación al menos en la etapa de reformulación del país bajo la égida militar.

La mímesis, si era problemática en El Padre mío, se vuelve ambigua en Jamás el Fuego Nunca y su ambigüedad, su paradoja, se vuelca en el quiasmo de un texto laberíntico: el paseo de la narradora por el espacio para llegar a los lugares en donde asea a los viejos y enfermos residuos de su tiempo, y por otra parte, en el laberinto de los tiempos, en que se analiza la propia juventud, la subjetividad de la época y los errores cometidos en los años 60 y 70, antes de la caída de Allende.

Es la caída de la célula política a manos de la dictadura, la caída del siglo y con él de algunas viejas y decadentes instituciones, como la pareja, la familia, como sistemas institucionalizados de relación. Es la caída de la célula biológica en la cual se prepara el tatuaje, la inscripción corporal requerida por Eltit como pago por la deuda de haber sido desbordados en una época que se terminó y que cae, no con una explosión, como dijo T. S. Eliot, sino con un gemido. 
Así, cuerpo político y cuerpo biológico establecen una suerte de correspondencia y diálogo cuyas señas se intercambian de una manera precisa, ósea.

Más aún, se podría decir que el cuerpo biológico, destrozado, es la mejor metáfora de esa pregunta por los sentidos históricos del siglo, por la pregunta de por qué no se pudo cursar el cambio social y el porqué de la caída en el fascismo, la fuerza de ese fascismo, impensadamente cruel que todavía abate la historia de Chile y cuyo modelo, desde un lugar fue Franco, y en otro, el neoliberalismo norteamericano y los brazos políticos de Nixon y Kissinger. La traición de los militares y su alianza con la clase burguesa dominante, el pacto de acaparamiento de alimentos, el canibalismo delator echando por tierra el mito de Chile solidario.

Pero la célula se extingue aún con otros pormenores, el regreso del conservadurismo en las relaciones personales y sociales dejando fuera las críticas de los años 60 a la noción de familia y la pareja, la revalorización machista sobre las capacidades reproductivas de las mujeres, el poder y biopoder de la Iglesia, particularmente el Opus Dei, y finalmente la muerte de la letra y el imperio tecnológico y comercial, que han conseguido hacer de este país un prometedor centro de exportaciones y de importaciones.

La revisión del siglo XX, como siglo de dos grandes guerras y una tercera guerra, no menos estruendosa, la guerra fría, que durara 40 años de historia, ha dejado fuera cualquier campo de valores, y ha descartado cualquier utopía o esperanza de un mejor, puesto que el siglo se permitió de manera estruendosa, el crimen fatricida. De este modo, los sectores que forman parte de él y que fueran sus actores políticos y culturales se preguntan asombrados por el curso abigarrado de los acontecimientos.

Es ese crimen el que campea sin justicia ni duelo, las sábanas de la pareja, recluida como nunca antes en una pieza, donde el hombre, inválido, enfermo, depende de la mujer, como nutridora y enfermera.

La cuenta pendiente que él paga con silencio y con enojo no solo es su ineficacia política, sino también la subordinación genérica a la que empujó a la mujer que lo acompaña. Como toda riña familiar, siempre hay un fantasma que se pudre y que clama venganza. En este caso, ese mortal espectro viene citado por la mujer, ella es la gestora de un cuerpo y la que, entre otras cosas, quisiera ser liberada: "Sí, recuerdo que te lo dije. Debemos tomar una decisión. Yo lloraba porque estaba aterrorizada, sabía lo que iba a suceder. Tenemos que apurarnos, llevarlo al hospital. O lo llevas tú o lo llevo yo. No, no, no, es imposible, imposible" (Jamás 32-33). 
Engastado en el discurso memorioso de la narradora, este pasaje aparece impecable y sin aviso previo. Es un cambio fuerte en los planos de la narración, pero sigiloso a pesar de que su peso semántico remece el silencio y la oscuridad como el hálito de la muerte ante cualquier atisbo de vida. Pero su llegada y su desarrollo, su inesperado fin certifica la existencia de la célula y materializa sobre la base de la complicidad el pacto de una pareja en abierta crisis.

Somos, así lo pactamos, una célula. Lo hicimos después que se hubo de consumar la muerte, no te muevas, ni la cabeza, ni menos los brazos, no ahora, porque era una muerte que nos competía y nos desgarraba. No lo llevamos al hospital, no parecía posible. Mis súplicas, lo sé, eran una mera retórica, una forma de disculpa o de evasión () No podíamos acudir con su cuerpo mermado y agónico, acezante y agónico, macilento y agónico, amado y agónico hasta el hospital, porque si lo hacíamos poníamos en riesgo la totalidad de las células porque caería nuestra célula y una estela destructiva iría exterminando el amenazado, disminuido campo militante. Aunque conocíamos las instrucciones, no sabíamos qué hacer con su muerte, dónde llevaríamos su muerte, cómo la legalizaríamos, ni sabíamos tampoco cómo salir de la inexistencia civil para ingresar con su cuerpo muerto a una sepultura en un cortejo funerario que nos podría delatar (Jamás 66).

Es la caída de la célula la que proyecta una crisis política llevándola hasta la inesperada maternidad: el hijo producto de la violación es el que muere a los dos años sin ser atendido por nadie, el hijo que él odia y quiere, porque a pesar de ser recordado como producto de violaciones y torturas, es una cita a la fertilidad de la especie, dispuesta a estallar en cualquier momento, no importa si está todo bien o todo mal. El hijo y su proyecto de vida, impedido, abortado a los dos años, el delirio final del hijo muerto y vivo en la mente de esa narradora, que relata íntegramente su destrucción y la destrucción de un cuerpo, que a la manera de un esquizo desconoce sus límites, los confunde como a los tiempos en un texto que termina con la conmovedora pregunta por la salida hacia otro tiempo mejor para reparar de algún modo el feroz siglo $\mathrm{XX}$. Un tiempo en que el hijo vive en el mundo virtual del deseo.

Finalmente cabe agregar que la relación violenta entre los géneros, su lucha a muerte a pesar de la simbiosis corporal plantea otro nudo patógeno correlativo a la ciudad y sus tiempos. Ese nudo patógeno es el cuerpo, tomado en todos sus planos, el cuerpo militante, el cuerpo embarazado, el cuerpo 
sobreviviente y castigado por la tortura, la mala suerte, las pérdidas. El hueso como el único resto, la última señal sobre la que se cancela el relato que pesquisa inexorablemente los fragmentos, los detalles, los nexos de la épica vivida desde la dictadura hasta la posdictadura, abriéndose paso en ese sitio para abrir un relato único, que disemina, agudo, el horror de la sobrevivencia, el cansancio de la lucha conjunta y solos a la vez, el clima de la catástrofe ante la falta de reconocimiento, de futuro y de reparación.

El relato y su clima angustioso perfectamente sostenido por Eltit exhibe en todos los planos que pone en escena la tensión normalidad/locura, en la sobrevivencia como el drama que padece el/la testigo de un crimen. Jamás El fuego Nunca abre la pareja como núcleo afectivo y social a la par que la política, como el escenario de la ambición y de las pequeñas traiciones y la eterna sospecha sobre el otro. Jamás el fuego Nunca concluye con la narradora psicótica que buscando un último punto de fuga a su precaria historia busca salir con su hijo entre los brazos. Jamás el fuego Nunca llega en todos sus capítulos al clímax del horror puesto que sabe que un malvado minotauro devorador, no el de la casa de Asterión, más ingenuo tal vez, sino borroso y múltiple, como las casas de la tortura de la CNI y su aparataje tecnológico del horror, ha instalado su sitio en su vida y que ese monstruo ha ensayado el crimen sobre sus amigos, sobre ella, sobre su pareja y su hijo.

La novela sabe que la historia pasa por los cuerpos y que el discurso no cambia fácilmente. La psicosis, la fuga, es tal vez la única respuesta a la patología del siglo XX y a la devoración del fascismo que gatilla en cada célula del cuerpo, no solo militar sino también en el odio del compañero que la espera solo para satisfacer su necesidad de cuidado y alimento. Todo eso recubierto de pliegues y recovecos son el recorrido barroco de la novela. La pregunta por el género comporta un sacrificio más a una historia ávida de sacrificios humanos.

Y también a la necesidad de reabrir el dilema de la memoria y el duelo, en un lugar en donde las autoridades pasean sus brillantes y pseudofelices cuerpos frente a una población que aún, pese al embate del sistema del capitalismo feroz, puede sentarse y recordar.

\section{BIBLIOGRAFÍA}

Baudrillard, Jean. "El éxtasis de la comunicación”. El posmodernismo. Ed. Hal Foster. Barcelona: Kairós, 2008. 
Borges, Jorge Luis. “La casa de Asterión”. 1949. El Aleph. Buenos Aires: Emecé, 1982.

Brito, Eugenia. Campos minados. Santiago: Cuarto Propio, 1990.

Eltit, Diamela. El padre mío. Santiago: Francisco Zegers editor, 1989.

El cuarto mundo. Santiago: Planeta, 1988.

Jamás el fuego nunca. Santiago: Planeta, 2007.

Lértora, Juan Carlos. Una poética de literatura menor: la narrativa de Diamela Eltit. Santiago: Cuarto Propio, 1993. 